Aus der Abteilung für Dermatologie und Syphilis an der $k, k$. deutschen Universitätspoliklinilk in Prag.

\title{
Zweiter Beitrag zur chemischen Untersuchung des Blutes rezent luetischer Menschen.*)
}

\author{
Von \\ Prof. Dr. Rudolf Winternitz, \\ Leiter der Hautabteihng an der dentschen Univorsitätspoliklinik in Prag.
}

\section{Wägungsbestimmungen.}

Die in einer früheren Arbeit') beobachtete Vermehrung einzelner Eiweißkörper im Blute nicht behandelter Luetiker (des floriden Sekundär-Stadiums) näher zu studieren, war der Zweck einer neuerlichen, mit derselben Methodik ${ }^{2}$ ) unternommenen Untersuchung.

Zur Verarbeitung gelangten Blutproben von sieben Luetikern und drei nicht luetischen, sonst bezüglich ihrer meisten Funktionen gesunden Personen. Von den ersteren genügten bloß drei der für die Untersuchung notwendigen Forderung, möglichst frisch, hochgradig und nicht oder nicht lange behandelt worden

) Nach einem auf dem XVI. internat. med. Kongresse (Budapest Sept. 1909) gehaltenen Vortrag.

1) R. Winternitz, Ein Beitr. z. chem. Unters. d. Bl. rez. luet. Menschen, Verhandlg. d. D. Derm. Gesellsch. X. Kongr. 1908 und A. D. S. 1908 XCIII.

2) Zur Gewinnung des Plasmas wurde statt Oxalats und Fluornatriums Hirundin (Jacobi) verwendet, von welchem ungefähr 1/3-1/2 cg in $2 \mathrm{com}$ phys. kalkfreier Kochsalzlösung aufgelöst, im Maßzylinder mit ungefähr 20-30 ccm frisch aus der Armvene aufgefangenen Blutes vermischt wurde. 
zu sein. Die in $\%$ berechneten Fibrinogenzahlen der Luetiker waren: $0.8,(0.9), 0.78,0.61,0.51,0.53$, also MittelzahI $0.68 \%$, jene der normalen Kontrollpersonen $0.6,0.39,0.45$, also Mittelzahl $\mathbf{0 . 4 8 \%}$. Von einigen dieser Fälle wurden auch die übrigen Eiweißfraktionen des Blutplasmas - Euglobulin, Gesamtglobulin und das Gesamteiweiß - durch Wägung bestimmt. Die folgende kleine Tabelle ${ }^{1}$ ) gibt die Zahlen für einen Luetiker (I u. II) und drei nicht luetische Kontrollpersonen. (III, IV, V.) Die Gesamteiweißbestimmungen sind bei dem Luetiker und dem ersten Kontrollfalle (III) zu klein ausgefallen, da die einmalige Koagulation (mit Zusatz von etwas Ammonsulfat), wie sie bei diesen Proben ausgeführt wurde, nicht genügt, um das gesamte Eiweiß zu erhalten:

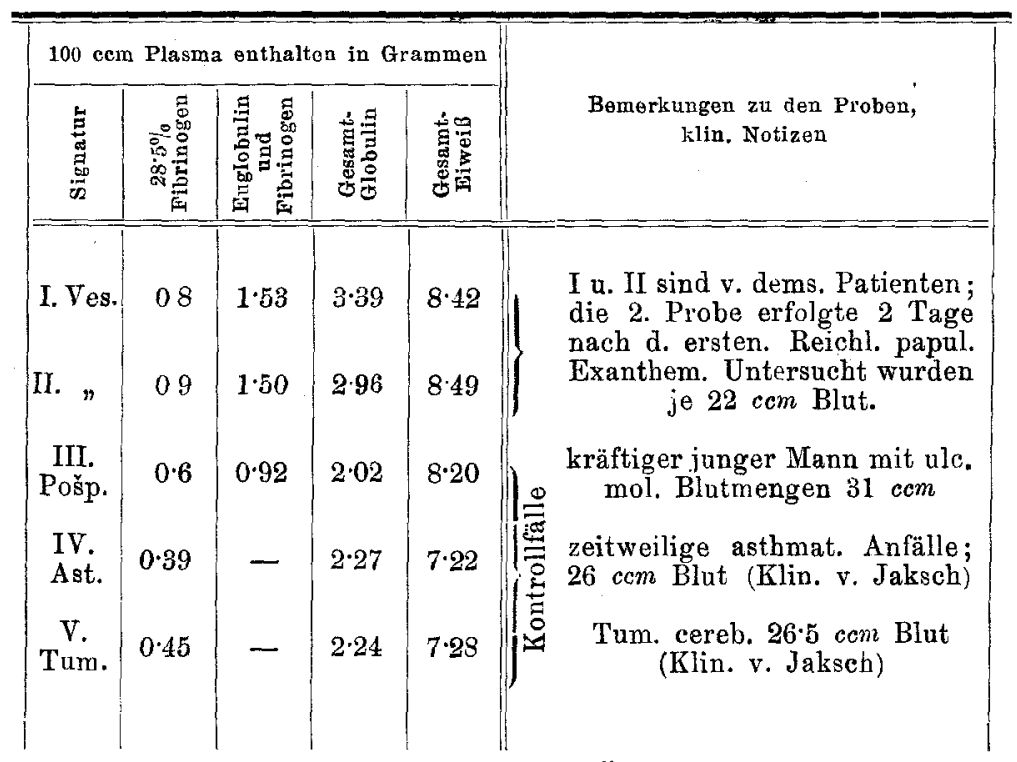

Auch aus diesen Zahlen ist in Übereinstimmung mit den vorjährigen ersichtlich, daß jene Eiweißfraktion, die mit einer $28.5 \%$ igen Ammonsulfatsättigung aus Blutplasma erhältlich ist, bei Luetischen vermehrt erscheint. Bei drei der Untersuchten waren diese Zahlen auffallend erhöht, bei vier nicht mißlungen.

1) Eine Reihe von Bestimmungen ist durch Anbrennen der Filter 
Zweiter Beitr. z. chem. Unt. des Blutes rez. luet. Menschen. 229

über die Norm größer; von den drei Kontrollpersonen fand sich einmal die Fibrinogenzahl recht groß, jener bei Luetischen gleich, bei den zwei anderen dagegen deutlich kleiner. Auch die Globuline und das Gesamteiweiß erschienen bei den Luesfällen gegenüber jenen bei den Kontrollpersonen vermehrt, doch kann dieses Resultat wegen der allzu geringen Zahl der (ohne Wägungsverluste) untersuchten Fälle nicht verallgemeinert werden.

\section{Refraktometrische Bestimmungen.}

Die häufigen Materialverluste bei der Wägungsmethode, namentlich aber der Zeitverlust, erschwerten die Untersuchung größerer Reihen von Fällen, durch welche erst eine halbwegs sichere Beurteilung ermöglicht wird. Deshalb wählte ich eine viel expeditivere und nach auf anderen Gebieten vorliegenden Untersuchungen sehr scharfe Methode für die quantitative Eiweißbestimmung, nämlich die mit dem Pulfrich'schen Eintauchrefraktometer ( $\mathrm{C} . \mathrm{Z}$ eiss ${ }^{1}$ ). Diese gestattet bei Berücksichtigung der Temperatur durch Bestimmung des Brechungscoeficienten den Gehalt einer Flüssigkeit an Salzen, Alkohol, Zucker, Koffëin u. a. mit größter Feinheit bis in die 2. Dezimale zu bestimmen. ${ }^{2}$ ) Sie wurde für den Harn (Grober, ${ }^{3}$ ) Strubell ${ }^{4}$ ) bei Nephritis und Diabetes, weiters fürs Blut benutzt und für klinische Zwecke, insbesondere durch $\mathrm{Strubell}$ und $R$ eiss ${ }^{5}$ ) dadurch sehr verbessert, daß sie die Lichtbrechung

1) Carl Z ei.ss Jena. Das Eintauchrefraktometer, III. Ausgabe 1905.

2) $\mathrm{H}$ an u š und $\mathrm{Chocenský} \mathrm{(Anw.} \mathrm{d.} \mathrm{Z.} \mathrm{Eintauchrefr.} \mathrm{i.} \mathrm{d.}$ Nahrungsmittelanal. Zeitschr. f. Unters. Nahr. u. GenuBmittel. 1906. B. 11. H. 6.; daselbst auch Literatur) fanden über $99 \%$ der angewendeten Koffëinmenge refraktometrisch wieder.

$\left.{ }^{3}\right)$ Grober, Quant. Zuckerbest. m. d. Eintauchrefr. Ztrbl. f. i. Med. 1900, Nr. 8.

4) Strubell A. Über e. neue Meth. d. Urin- und Blatuntersuchg. Arch. f. klin. Med. LXIX, p. 521 u. Vortr. auf d. XVIII. Kung. f. innere Med. Wiesbaden 1900.

5) Reiss Diss. Straßburg 1902; derselbe: Der Brechungskoefi. d. Eiweißkörper d. Blutserums, H o f me is ters Beiträge z: chem. Phys. IV 1904, 150. Ders.: Eine neue Meth. d. quantit. Eiweißbest. Arch. f. exp. Path. u. Pharmak. 41 1904, p. 19; ders. Verh. d. 76. Vers. deutsch. Naturf. u. Ärzte Breslau 1904, p. 36. 
für $1 \%$ Eiweiß bestimmten und durch entsprechende Kammern (Hilfsprismen) die Untersuchung ron einem einzigen (großen) Tropfen Blutserum ermöglichten. Reis sat überdies die umständliche Umrechnung der Skalenteile des Instruments auf Eiweißprozente ungemein erleichtert. Bei kurzdauernder Einübung ist die Benützung des Eintauchrefraktometers Jedem leicht möglich und dürfte in methodischer Weise für größere Reihen von Fällen angewendet, zu wichtigen und relativ mühelosen Ergebnissen führen. So für die Lues, für welche hier die ersten methodischen Bestimmungen vorgelegt werden.

Von dermatologischer Seite ist diese Methode noch wenig verwendet worden. Kreibich ${ }^{\mathbf{1}}$ ) hat sie behufs Eruierung des Eiweißgehaltes von Blaseneffloreszenzen benutzt, um einen Ausdruck für die verschiedene Genese derselben - Stauungsödem, Entzündung, Angioneurose - zu gewinnen. Weiters ${ }^{2}$ ) hat er Blutserum untersucht und gefunden, daß bei verschiedener Entnahme - Aderlaß, Fingerbeerenstich, Skarifikation - in der Regel gleiche, selten verschiedene Skalenaufschläge erhalten werden, was nach ihm an einer verschiedenen Form der Gerinnung liegt. Ich selbst habe wegen experimenteller Einfachheit und Einheitlichkeit stets nur einen Entnahmsort, die Fingerbeere, gewählt, da der Aderlaß umständlich, die Biersche Ansaugung aber zu viel Gewebsflüssigkeit fördert.

\section{Verfahren.}

In die mit Benzin oder Alkohol (Äther) gereinigte Fingerbeere, gewöhnlich des linken Mittelfingers wurde ein kaschierter Stecher bis zu einer Tiefe von $6 \mathrm{~mm}$ in der Gegend der Fingergefäße, d. i. seitlich, sehr rasch eingestochen. Das hierauf hervorquellende Blut - Drücken oder Pumpen ist grundsätzlich zu vermeiden - wurde in einem Gefäßchen A aufgefangen, das einige ccm falite, nach oben becherförmig erweitert, nach unten verjüngt war. Sobald 2-3 ccm Blut eingeflossen waren, wurde A mit Kork-

I) Kreibich u. Polland. Refrakt. Unters. exsud. Derm. A. D. S. LXXV. $1 \mathrm{H}$.

VI. Nr. 6.

2) Kreibich: Übes d. refrakt. Werte d. Blutser. Fol. bämat. 1907, 
stöpsel $^{1}$ ) verschlossen. Hierauf wurde in einer kleinen Glasdose (von 2-3 cm Durchmesser), welche $1 / 2-1 / 3 \mathrm{cgr}$ Hirudin enthielt, eine zweite Blutportion aufgefangen, mit dem Hirudin durch Umrühren mit einem Glasstäbchen gemischt und in ein dem A gleiches Gefäßchen B gebracht und verschlossen. Diese Prozedur ist bei rasch tropfendem Blut in 1-2 Minuten durch eine Person leicht ausführbar, so daß ein Verlust durch Verdunsten ausgeschlossen ist.

$A$ und $B$ wurden nun in einer elektrischen Zentrifuge durch 5-10 Minuten zentrifugiert, ${ }^{2}$ ) wodurch in A Serum, in B Plasma absolut klar (sehr selten hämolytisch) erhalten wird. Die Zentrifugate wurden mit armierter ${ }^{3}$ ), verjüngter Glaskapillare, deren Lichtung und Länge für einen großen Tropfen genügte, abgesogen. $\mathrm{Zu}$ jeder Probe wurde eine andere der vorrätig gehaltenen und sorgfältig gereinigten Kapillaren verwendet.

Der Tropfen wird nun auf die Schieffäche des Hilfsprismas gebracht, auf letztere die entsprechende des Refraktometers aufgesetżt, das ganze um die Achse gedreht und mit dem mit Glasfenster versehenen metallenen Zylindergefä $\beta$ verschlossen. Diese Hantierung erschien etwas bequemer als die bei $\mathrm{Ze}$ is angegebene. Anfänglich habe ich hierauf sofort eine Bestimmung vorgenommen, erst als ich durch verschiedene Differenzen über die (übrigens schon von $\mathrm{Zeiss}$ und $\mathrm{Reiss}$ hervorgehobene) Bedeutung der Temperaturkonstante belehrt worden, habe ich behufs Erlangung der Normaltemperatur von $17.5^{\circ} \mathrm{C}$. folgenden Vorgang beobachtet.

Ich kühlte die Zentrifugierröhrchen und den Metallzylinder des Refraktometers in entsprechend temperiertem Wasser, Arbeiten.

1) Strubell 1. c. rät wegen der störenden Verdunstung rasches

5) Vor dem Zentrifugieren empfiehlt sich die Lüftung der Stöpsel resp, die Reinigung derselben und der Stöpselstellen der Gläschen, um das Verbleiben von Blut daselbst zu verhüten, da letzteres nach dem Zentrifugieren in das oben stehende Zentrifugat gelangen und das Resultat träben konnte. Auch war es einigemal notwendig, in den Serumgläschen die Blutkuchen mit der Platinnadel abzulösen und nochmals zu zentrifugieren. Aspiration.

3) Kautschukschlauch und Kugelsicherung behufs Vermeidung der 
welches ich auch bei mehreren einander folgenden Proben zur Reinigung der Glasflächen des Apparates benützte. Die Untersuchung selbst wurde zumeist bei der Umgebungstemperatur von $17-18^{\circ}$ C., d. i. der Temperatur des Kühlraumes des pharmakolischen Institutes durchgeführt. Ich habe mich überzeugt, daß dieses Vorgeken zumeist viel rascher als in $10 \mathrm{Mi}$ nuten durchgeführt werden konnte, d. i. der Zeit, die nötig ist, um in dem dem Refraktometer beigegebenen Wasserbade die gewünschte konstante Temperatur zu gewährleisten. Übrigens habe ich einen Teil der Bestimmungen auch in dem konstanten Wasserbade ausgeführt. Die ersten Bestimmungen, die ich anstellte, sind leider ohne Berücksichtigung der Temperatur vorgenommen. Letztere dürfte $20^{\circ} \mathrm{C}$. oder etwas mehr betragen haben. Spätere bei einer anderen als der Normaltemperatur ron $17.5^{\circ} \mathrm{C}$. aufgenommene, sind auf letztere umgerechnet worden, was leicht möglich war, da Kontrollbestimmungen zeigten, daß ein Unterschied von $3^{0} \mathrm{C}$. (also Untersuchung bei $20^{\circ}-20^{\circ} \tilde{5}^{0}$ ) ungefähr einer Differenz von 1 Skalenteil, ein Unterschied von $6^{\circ} \mathrm{C}$. (also Untersuchung bei $23^{\circ}-24^{\circ}$ ) einer Differenz von 1.3 Skalenteilen entspricht, so daß letztere Zahlen den bei solchen Versuchen gefundenen Skalenwerten zuzurechnen waren. Bei Proben, welche im Intervalle ron $17-18.5^{\circ} \mathrm{C}$ aufgenommen waren, habe ich keine Korrektur vorgenommen, da nach meiner Erfahrung so kleine Temperaturunterschiede keine Differenz der Skalenwerte ergeben.

Durch Umrechnung meiner Skalenzahlen auf die entsprechenden Eiweißprozente (nach Reiss) erhielt ich somit für jeden meiner Fälle zwei Zahlen, von denen die eine dem Serumeiweiß, die andere dem Gesamteiweiß entsprachen. Die letztere Zahl ist aber nach Reiss kleiner als der Wirklichkeit ententspricht, denn merkwürdigerweise ist der Brechungsindex der das Gesamteiweiß enthaltenden Lösung kleiner als jener einer Lösung der einzelnen Eiweißfraktionen ${ }^{1}$ ) (Globuline, Albumine).

1) Reiss l. c. Hofme isters Beitr. z. chem. Phys. IV. 1904, 150 gibt folgenden Brechungsindex f. d. verschiedenen Eiweißfraktionen an:

Euglobulin Pseudoglob. I. Pseudoglob. II. Kryșt. Alb. 0.0023

$00022 \quad 0.0023$

am. Alb. Gesamteiwei 3 
Die Differenz der so erhaltenen Eiweißwerte des Plasmas und Serums habe ich als Fibrinogen angenommen, was natürlich zwei Fehler in sich schließt. 1. Haftet dem Serum ein kleiner Fibrinogenrest an und ist es wohl möglich, ja fast. sicher, daß dieser Rest beim pathologischen Serum (also auch bei der Lues) größer sein kann; 2. ist dem früher gesagten zufolge der durch den Brechungscoefficient gewonnene Wert für das Gesamteiweib zu klein. Beide Fehler zusammen verkleinern somit die Differenz, d. i. den Fibrinogenwert. Trotzdem muß sich, wenn Plasma und Serum bei Luetischen in deutlicherer Weise von einander differieren, als bei Gesunden, dies auch im Fibrinogenwert ausdrücken.

\section{Refraktometrische Beobachtungen an gesunden und luetischen Personen.}

Aus später anzuführenden Gründen wurde Blut untersucht.

1. Von gesunden Menschen von 20-30, selten bis $40 \mathrm{Jahren}$, ausnahmsweise von über 40 Jahre alten.

2. Von Leuten ${ }^{1}$ ) in der 2. Inkubationsperiode (Sklerose, Adenitis; 5.-8. Infektionswoche).

3. Von Patienten mit floriden Allgemeinerscheinungen. (papul. Exantheme, Condyl. lat., Plaques etc.).

4. Von einzelnen Patienten mit gummösen Erscheinungen.

5. Von Luetikern im Latenzstadium.

Wo möglich, untersuchte ich im Hungerzustande der Patienten, also vor dem Mittag- oder Abendessen. Bei Patienten, die ich nur einmal in der Sprechstunde sah, konnte ich dieses für die Plasmauntersuchung wohl wichtige Moment nicht immer einhalten.

1) Die Patienten gehörten an: der Hautabteilung der UniversitätsPoliklinik, der Klinik des Herrn Prof. Kreibich, der mit größter Bereitwilligkeit die Untersuchung gestattete, und meiner Privatklientel. 
I. Normalfälle.

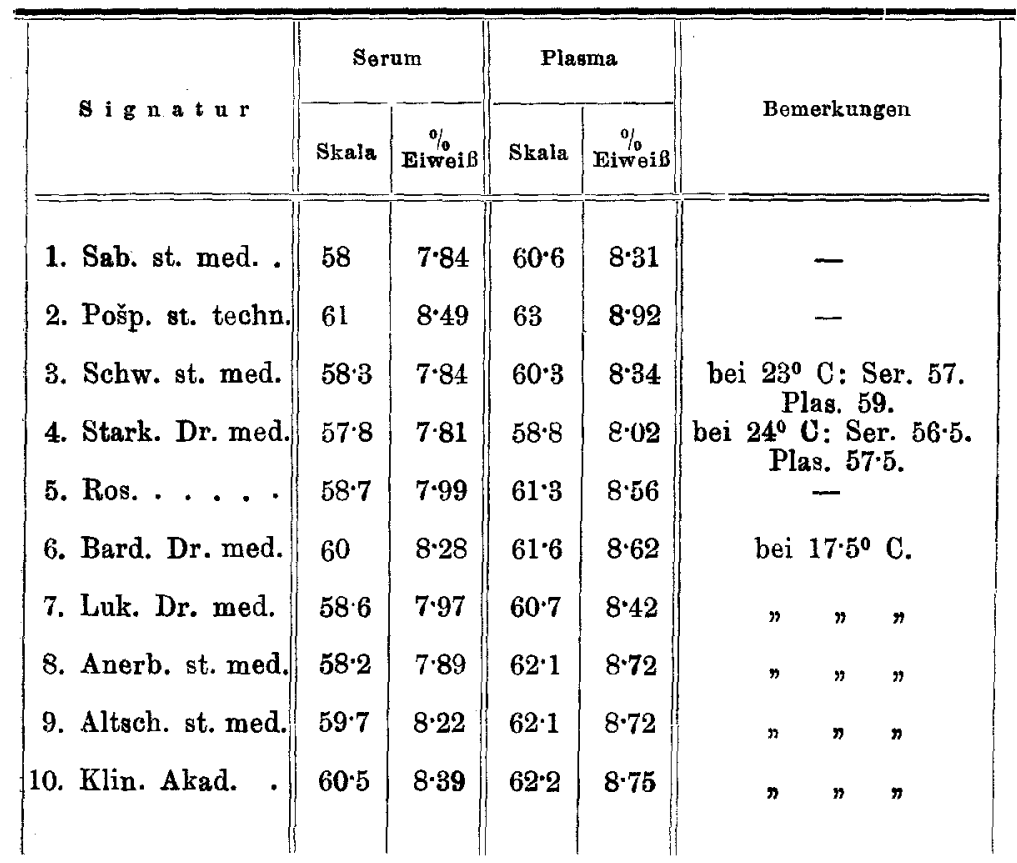

Resumé: Bei 10 normalen jungen Männern ${ }^{1}$ ) schwankten die refraktometrischen Skalenwerte bei ungefähr $17 \cdot 5^{\circ}$

bei Serum zwischen $\mathbf{5 7 . 8}$ (Fall 4) bis 61 (Fall 2), die prozentischen Eiweißwerte

$$
\text { für Serum von } \mathbf{7 . 8 1}-8.49 \% \text {, }
$$

also Werten, welche bezüglich des Serums den von $R$ e is $s$ mit dem Refraktometer, von Leven, Ha mmarsten, v. Jaksch

1) Es soll nicht mehr verschwiegen werden, daß bei vereinzelten Fällen namentlich die Plasmawerte größer ausfielen.

$\begin{array}{lcc}\text { 1. Wiech, Dr. med. } & 59 & 64 \\ \text { 2. Müll st. med. } & 60 & 65 \\ \text { 3. Pol. Dr. med. } & 59 & 62 \\ \text { 4. Sgal. } ~ & 61 & 63 \cdot 1 \\ \text { 5. Schwarzk. st. med. } & 58.1 & 63 \cdot 1\end{array}$

Doch waren die Proben mangelhaft; bei $1-3$ habe ich die Methode noch nicht beherrscht, Fall 4 hat $1 \frac{1}{2}$ Stunden vorher reichlich Milch genossen und $3^{1} / 2$ Stunden vorher reichlich Fleisch (etc.) gegessen, bei Fall 5 war das Plasma hämolytisch. 
mit andern Methoden für normale, gesunde Menschen angegebenen ziemlich gut entsprechen. Die Differenz der prozentischen Eiweißwerte von Plasma und Serum betrug in den vorangegangenen Versuchen: $0.47,0.52,0.50,0.21,0.57,0.34,0.45,0.83,0.50,0.36$, also Zahlen, welche jenen mit der Wägungsmethode erhaltenen, Eingangs aufgeteilten $0 \cdot 6,0 \cdot 39,0 \cdot 45$ sehr gut entsprechen. Nur eine dieser Differenzzahlen 0.83 (Fall 8) ist auffallend hoch gewesen. Die erhaltenen Differenzzahlen (Fibrinogenwerte) sind größer als die im Vorjahre mit der Wägungsmethode gewonnenen und stimmen mit den von $L e$ wins $\mathrm{ky}^{1}$ ) für den gesunden Menschen erhaltenen Fibrinogenzahlen überein.

Die Mittelwerte dieser 10 Normalbestimmungen sind in Skalenteilen in Eiweibproz.

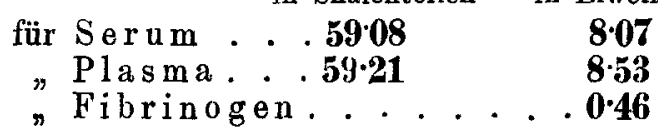

II. 2. Inkubationsperiode (Sklerose, Adenitis etc.).

\begin{tabular}{|c|c|c|c|c|c|}
\hline \multirow[b]{2}{*}{ Signatur } & \multicolumn{2}{|c|}{ Serum } & \multicolumn{2}{|c|}{ Plasma } & \multirow[b]{2}{*}{ Bemerkungen } \\
\hline & Skala & $\begin{array}{c}\% \\
\text { Eiwei } B\end{array}$ & Skala & $\begin{array}{c}\% \\
\text { Eiwei }\end{array}$ & \\
\hline 1. Schmut. & 60 & 8.28 & 64 & $9 \cdot 14$ & Inf.v. 5-6Woch. Skler. \\
\hline 2. N. N. & $61 \cdot 5$ & $8 \cdot 60$ & 63 & 8.92 & mult. Sklerosen; Aden. \\
\hline 3. Vlas. . . . & 60 & $8 \cdot 28$ & 64 & $9 \cdot 14$ & lok. Papeln (prim.) \\
\hline 4. Hor. . & $60 \cdot 5$ & $8 \cdot 39$ & 63.4 & $9 \cdot 01$ & ulc. ind.; 2 harte \\
\hline 5. Dvor. . & $63 \cdot 5$ & $9 \cdot 03$ & $64: 3$ & $9 \cdot 20$ & Skler. c. aden.; Phar. \\
\hline 6. Ves. . . & $60 \cdot 7$ & $8 \cdot 43$ & 62 & $8 \cdot 71$ & Skler. c. ad. skler. \\
\hline n & $61 \cdot 25$ & 8.55 & 6425 & $9 \cdot 19$ & Ders. 8 Tage später. \\
\hline 7. St. & 60.5 & $8 \cdot 39$ & $63 \cdot 5$ & $9 \cdot 02$ & Skler. c. aden. \\
\hline 8. Dut. . . & 64 & $9 \cdot 14$ & 66 & $9 \cdot 56$ & L. C.v.6W. Skl. Bal.Ph. \\
\hline 9. Reit. . . & 62 & $8 \cdot 71$ & $63 \cdot 5$ & 902 & bei $21^{\circ}$ C. Ser. 61 . \\
\hline 10. W. . . & $64 \cdot 4$ & $9 \cdot 22$ & $66 \cdot 5$ & $9 \cdot 67$ & $\begin{array}{c}\text { Skler. c. Ad.; bei } \\
17.5^{\circ} \mathrm{C} .\end{array}$ \\
\hline
\end{tabular}

1) Lewinsky, Pflügers Archiv 1903, B. C. p. 611. 
Resumé. Die Skalenwerte schwankten in der 2. Inkubationsperiode

für Serum zwischen 60 (Fall 3) und 63.5 (Fall 5)

Plasma "62 (Fall 6) , 665 (Fall 10);

die $\%$ Eiweißwerte

$$
\begin{gathered}
\text { für Serum zwischen } \mathbf{8 . 2 8} \text { u. } \mathbf{9 \cdot 2 2} \% \\
\text { "Plasma } " \quad \mathbf{8 . 7 1} \text { u. } \mathbf{9 \cdot 6 7 \%}
\end{gathered}
$$

Die Fibrinogenzahlen betrugen in den 10 Proben: 0.86 , $0.23,0.86,0.62,0.17,0.28,0.64,0.63,0.42,0.31,0.45$, also im ganzen um ein geringes höher als bei den Normalfällen.

Die Mittelwerte dieser 10 Bestimmungen in der 2. Inkubationsperiode sind in Skalenwerten in Eiweißproz.

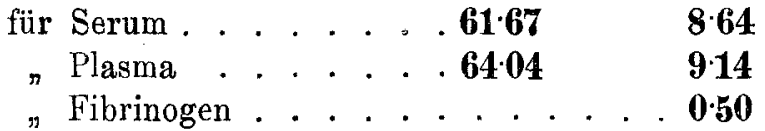

\begin{tabular}{|c|c|c|c|c|c|}
\hline \multirow[b]{2}{*}{ Signatur } & \multicolumn{2}{|c|}{ Serum } & \multicolumn{2}{|c|}{ Plasma } & \multirow[b]{2}{*}{ B e merku ugen } \\
\hline & 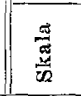 & $\mid \begin{array}{r}9 \\
00 \\
0 \\
0\end{array}$ & 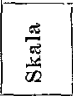 & $\mid \begin{array}{r}0 \\
0 \\
0 \\
0\end{array}$ & \\
\hline 1. Wint. & $4 \cdot 5$ & $9 \cdot 2$ & 1 & $9 \cdot 58$ & oBe Skler Aden. reich. mac. Ex. \\
\hline 2. J, B.* & $1 \cdot 4$ & & 1.3. & & 65.8 Plasma. \\
\hline 2. & & & & & 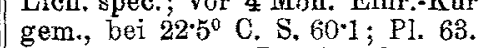 \\
\hline 3. A. Wran* & $63 \cdot 2$ & 8.96 & $64 \cdot 8$ & $9 \cdot 30^{\prime}$ & Lues. cut. mac. Papeln ad gen. \\
\hline 4. Sal. & 6833 & $8 \cdot 98$ & & $9 \cdot 45$ & Leucodermareste; Ule. tons. ohne \\
\hline 5. Ofn.* & 61.7 & 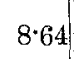 & $64 \cdot 15$ & $9 \cdot 17$ & $\begin{array}{l}\text { Temperaturbestimmung. } \\
\text { Skler. Ad. ikter. reichl. mac. }\end{array}$ \\
\hline 6. Slov.* & $65 \cdot 1$ & 9.37 & 67.8 & $9 \cdot 94$ & $\begin{array}{l}\text { Ex. keine Temper. } \\
\text { Ex. mac. pap.; keine Temperatur- }\end{array}$ \\
\hline 7. Vod.* & 62 & 8.71 & $69 \cdot 5$ & $10 \cdot 30$ & $\begin{array}{l}\text { bestimmung. } \\
\text { reichl. Papeln; keine Temperaturb. }\end{array}$ \\
\hline 8. Re. & 68 & $9 \cdot 9$ & $71 \check{0}$ & $10 \cdot 73$ & A " \\
\hline 9. Ham. & $65 \cdot 5$ & $9 \cdot 4$ & 67.75 & $9 \cdot 98$ & Papeln, Alop. Inf. über $1 / 2$ \\
\hline 10. j. M.* & 62 & $8 \cdot 71$ & $69 \cdot 5$ & $10 \cdot 30$ & $\begin{array}{l}\text { oncichl. papul. Ex.; keine Temper. } \\
\text { rexp. }\end{array}$ \\
\hline 11. Hlav. & $61 \cdot 8$ & $8 \cdot 6$ & 98 & $10 \cdot 36$ & $" \quad "$ \\
\hline 12. A. Igl.* & $66 \cdot 35$ & $9 \cdot 3$ & 35 & $10 \cdot 27$ & bei $20^{3} /{ }^{0}{ }^{0}$ C. Ser. $65 \cdot 35$; Pl. 68.35 . \\
\hline
\end{tabular}

III. Lues papulosa. 
Zweiter Beitr. z, chem. Unt. des Blates rez. luet. Menschen. 237

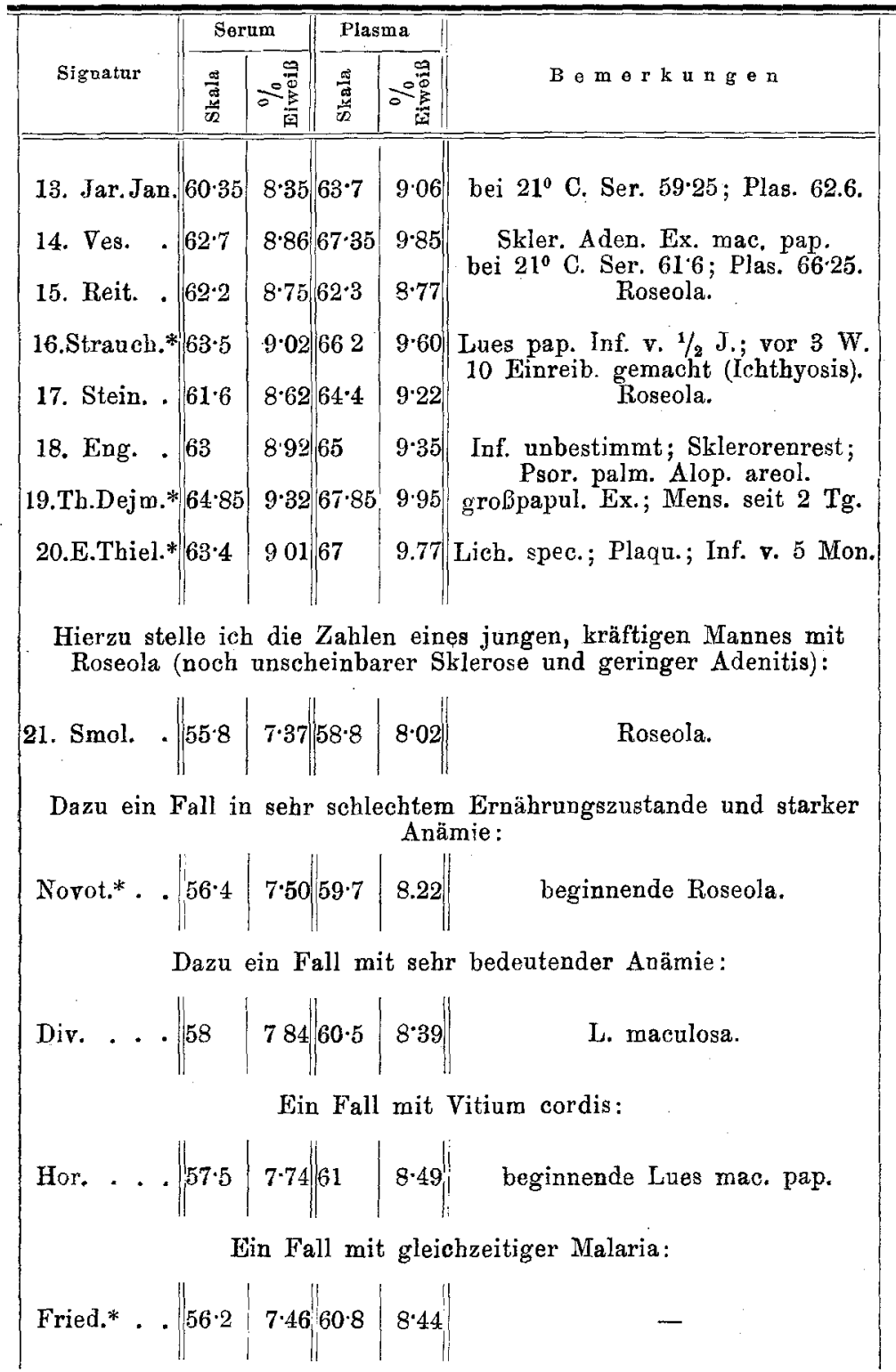

Resumé. Bei den 21 Proben dieser Reihe ${ }^{1}$ ) schwankten die Skalenwerte:

1) Fall 21 verschiebt die untere Grenze für Serum auf $55 \cdot 8$, Plasma 58.8, \% Eiweiß für Serum $7 \cdot 37 \%$, für Plasma $8.02 \%$; diese Werte 
für Serum zwischen 6035 (Fall 13) und 68 (Fall 8) "Plasma , 62:3 (Fall 15) \# 71.5 (Fall 8)

Die \% Eiweißwerte:

für Serum zwischen $8.35 \%$ und $9.99 \%$

$$
\text { "Plasma } " \mathbf{8} \cdot \mathbf{7 7} \%, \mathbf{1 0} 3 \mathbf{3 7} \%
$$

Die Mittelwerte dieser 21 Bestimmungen bei Lues papulosa sind in Skalent. in Eiweißproz.

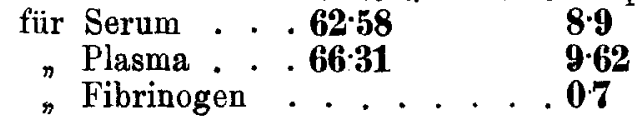

resp. wenn die vier niedrigen Werte (Fall 22, 23, 24, 25) zugerechnet werden, sind die Mittelwerte

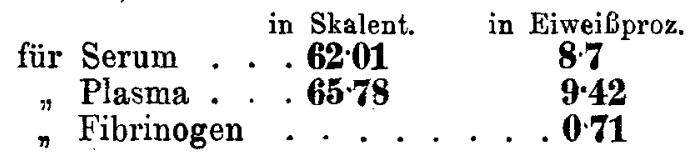

Für den prozentischen Fiweißgehalt von. Serum und Plasma bei Gesunden und Kranken ergibt sich somit folgende Übersichtstabelle:

\begin{tabular}{|c|c|c|c|}
\hline & Serum & Plasma & Fibrinogen $\left.{ }^{2}\right)$ \\
\hline Normal..... & $8.07 \%$ E. & $853 \%$ E. & $0.46 \%$ \\
\hline II. Inkubat. . . . & $8.64 n$, & 9.15n & $0.50 "$ \\
\hline Lues papulosa... & $\begin{array}{c}8 \cdot 92 \text { " } \\
(8 \cdot 70) \text { » }\end{array}$ & $\begin{array}{c}9 \cdot 62 n \\
(9 \cdot 42) "\end{array}$ & $\begin{array}{c}0.7 \\
(0 \cdot 71)\end{array}$ \\
\hline
\end{tabular}

Diese Reihe zeigt ein stetiges Ansteigen.

In deutlicher Weise ist letzteres auch bei einzelnen Fällen ersichtlich, die ich mehreremal in verschiedenen Zeiten untersuchen konnte:

sind im Resumé nicht verzeichnet, um die Übersichtlichkeit nicht zus stören, doch sind sie zur Berechnung der Mittelwerte natürlich verwendet worden.

1) Wie ersichtlich, stimmen die heucr mit der Wägungsmethode erhaltenen und die aus den Refraktometerzahlen berechneten Fibrinogenbefunde mit einander gut überein. (S. die Eingangs mitgeteilten Mittelzablen.) 
Zweiter Beitr. z. chem. Unt. des Blutes rez. luet. Menschen. 239

\begin{tabular}{|c|c|c|c|c|c|}
\hline & \multicolumn{2}{|c|}{ Serum } & \multicolumn{2}{|c|}{ Plasma } & \\
\hline & Skala & $\% \mathbf{E .}$ & Skala & $\% \mathbf{E}$ & \\
\hline 1. Ves. Lad. $21 . / \mathrm{V}$. & $60 \cdot 7$ & $8 \cdot 43$ & 62 & $8 \cdot 71$ & Skler. Adenit. \\
\hline $29 . / \mathrm{V}$ & $61 \cdot 25$ & $8 \cdot 55$ & $64 \cdot 25$ & $9 \cdot 19$ & ” \\
\hline 15./VI. & $62 \cdot 7$ & $8 \cdot 86$ & $67 \cdot 35$ & $9 \cdot 85$ & Ex. mac. pap. \\
\hline 1. St. . . 28./V. & 60.5 & $8 \cdot 39$ & $63 \cdot 5$ & $9 \cdot 02$ & Skler. Ad. Inf. üb. 8 W. \\
\hline 9./VII. & $61 \cdot 6$ & $8 \cdot 62$ & $64 \cdot 4$ & $9 \cdot 12$ & Exanth. mac. pap. \\
\hline
\end{tabular}

In zwei anderen Fällen war ein solches Ansteigen nicht ersichtlich; in einem Falle, der mit einer viel jauchigen Eiter absondernden Balanitis und Phimose kompliziert war, war sogar ein Absinken der Eiweißwerte zu verzeichnen.

\section{Lues gummosa.}

Die Skalenwerte der wenigen Fälle sind nicht gleichmäßig.

\begin{tabular}{|c|c|c|c|c|c|}
\hline \multirow[b]{2}{*}{ Signatur } & \multicolumn{2}{|c|}{ Sernm } & \multicolumn{2}{|c|}{ Plasma } & \multirow[b]{2}{*}{ Bemerknng } \\
\hline & 量 & $\therefore$ & 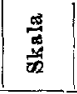 & $\mid \begin{array}{c}0 \\
0 \\
0\end{array}$ & \\
\hline 1. Vob. . & $61 \cdot 8$ & 8.66 & $64 \cdot 4$ & $9 \cdot 22$ & Inf. v. 4 J. \\
\hline 2. Sal. & $63 \cdot 3$ & 8.98 & $65 \cdot 5$ & $9 \cdot 45$ & ident. mit Fall 4 der III. Tabelle; \\
\hline 3. Fleischm. & $60 \cdot 5$ & $8 \cdot 39^{\prime \prime}$ & & $8 \cdot 71$ & $\begin{array}{c}\text { Infekt. über } 2 \text { Jahre. } \\
\text { Inf. v. } 4 \text { J.; Ep. luet. ut. v. } 3 \text { J. }\end{array}$ \\
\hline 4. Stan. . & $57 \cdot 3$ & $7 \cdot 67$ & & $8 \cdot 43$ & $\begin{array}{l}\text { gegenw. Gummad.Penis u. E. ch.luet. } \\
\text { Inf. v. über } 2 \text { J.; Lues gumm. }\end{array}$ \\
\hline 5. N. N. & $58 \cdot 4$ & $7 \cdot 93$ & $60 \cdot 5$ & $8 \cdot 31$ & $\begin{array}{c}\text { test. keine Temp. } \\
\text { Inf. v. } 15 \mathrm{~J} . ; \text { kleines Gumma am }\end{array}$ \\
\hline 6. Pol. & 58.5 & $7 \cdot 96$ & $60 \cdot 5$ & 8.39 & $\begin{array}{l}\text { Unterschenkel, keine Temper. } \\
\text { Inf. vor } 20 \mathrm{~J} ; \text { kleines Gumma der }\end{array}$ \\
\hline 7. Ber. . . & $62 \cdot 2$ & 8.75 & $68 \cdot 35$ & $10 \cdot 06$ & $\begin{array}{l}\text { Thoraxhaut. } \\
\text { d. tarda; } 17 \mathrm{j} \text {. Mädchen, seit }\end{array}$ \\
\hline & & & & & $\|$ 1/2 J. Periost gumm. ut. (Osteomyel.?) \\
\hline
\end{tabular}

Resumé: Die Skalenwerte schwanken: für Serum von $57 \cdot 3$ bis $62 \cdot 2$

Die \% ischen "Eiweißwerte "Plasma \# $605 \% 68.35$

für Serum von 7.67 bis 8.75

"Plasma \# $8.37,10 \cdot 06$ 
Ich unterlasse bei der geringen Zahl von Fällen gummöser Lues Durchschnittswerte zu geben und bemerke nur, da $\beta$ bei den niedrigen Werten (Fall 5 und 6) lange Zeit - 15 und 20 Jahre - nach der Infektion verflossen und nur vereinzelte, geringe Lokalerscheinungen bei sonstiger anscheinender Gesundheit waren; bei den Fällen mit etwas oder stärker erhöhten Zahlen (Fall 1, 2, 3, 7) die Infektion jünger und die Erscheinungen zum Teil sehr bedeutend waren. Im Falle 6 hereditiäre Lues mit Periostitis tib. utr. (wohl auch Osteomyelitis) und Gonit utr. war keine Ullzeration, daher auch kein Fiweißabgang nach außen vorhanden.

\section{Latenzperiode.}

Hier sind 2 Fälle der frühen, zumeist jedoch solche der späten Latenzperiode verzeichnet. Bei vereinzelten waren verdächtige Symptome vorhanden; ein Fall ist eine fortschreitende Tabes.

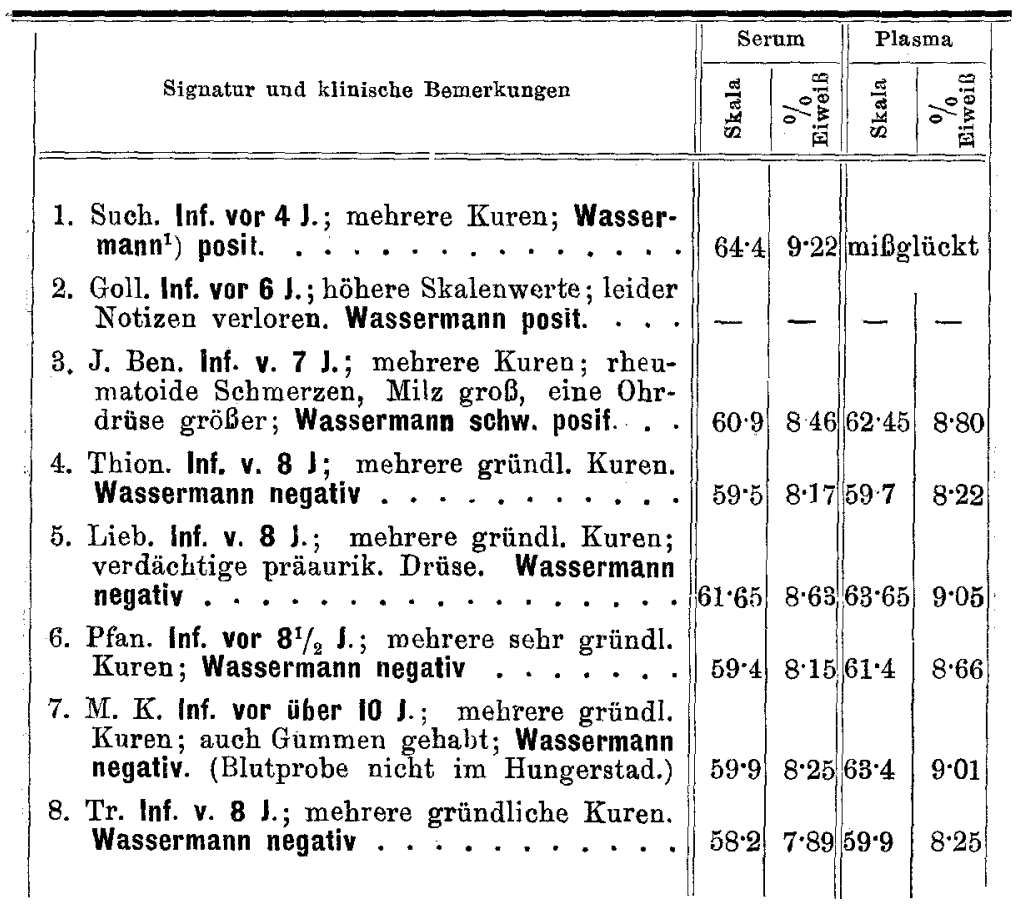

1) Die Wassermannproben wurden von Doz. E. Weil ausgeführt. 


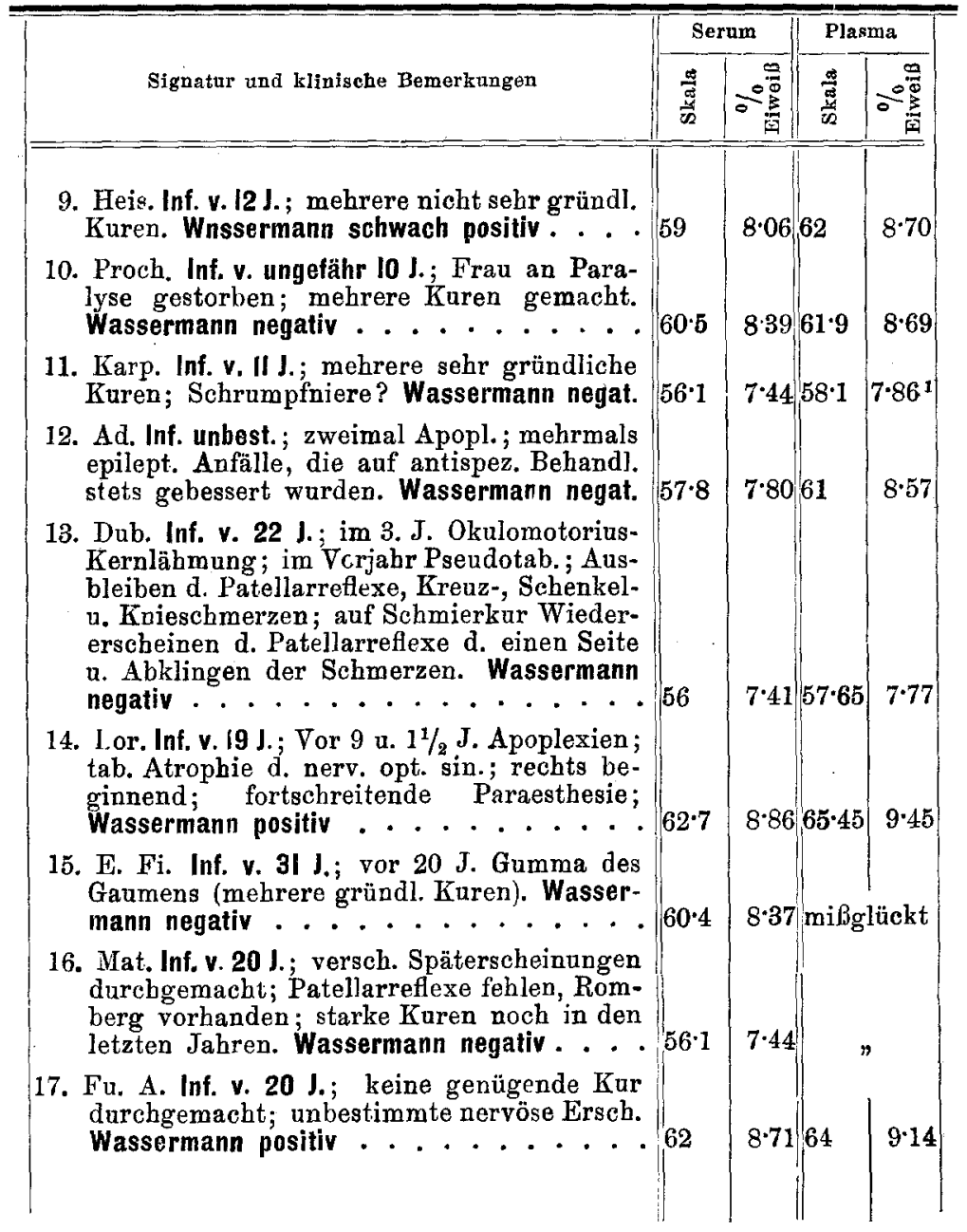

Von den voranstehenden 17 Fällen gaben 7 kleine Skalenresp. Eiweißwerte, die eventuell noch kleiner als jene bei Normalfällen waren, so Fall 4, 6, 8, 11, 12, 13, 16; die Fälle der früheren Latenzperiode $(1,2)$ sowie einzelne der späten,

1) Die Kleinheit der Eiweißzahlen, die bei diesem Falle, dem einzigen an einer Nierenerkrankung Leidenden, gefunden wurden, stimmtemit den bei Nephritis erhobenen Befunden von v. Jaksch, Limbeck und Friedel Pick (D. m. W. 1894, Nr. 27), Reis s l. c. u. a. überein. 
welche (verdächtige) Symptome boten, hatten entweder wenig oder stärker erhöhte Skalen- d. i. Eiweißwerte.

\section{Quecksilberbehandlung.}

Einzelne Fälle, die ich nach einer gewissen Behandlungszeit untersucht habe - mehr konnte ich bei meinem Material nicht aufbringen - zeigten im allgemeinen nicht so hohe Werte als die unbehandelten.

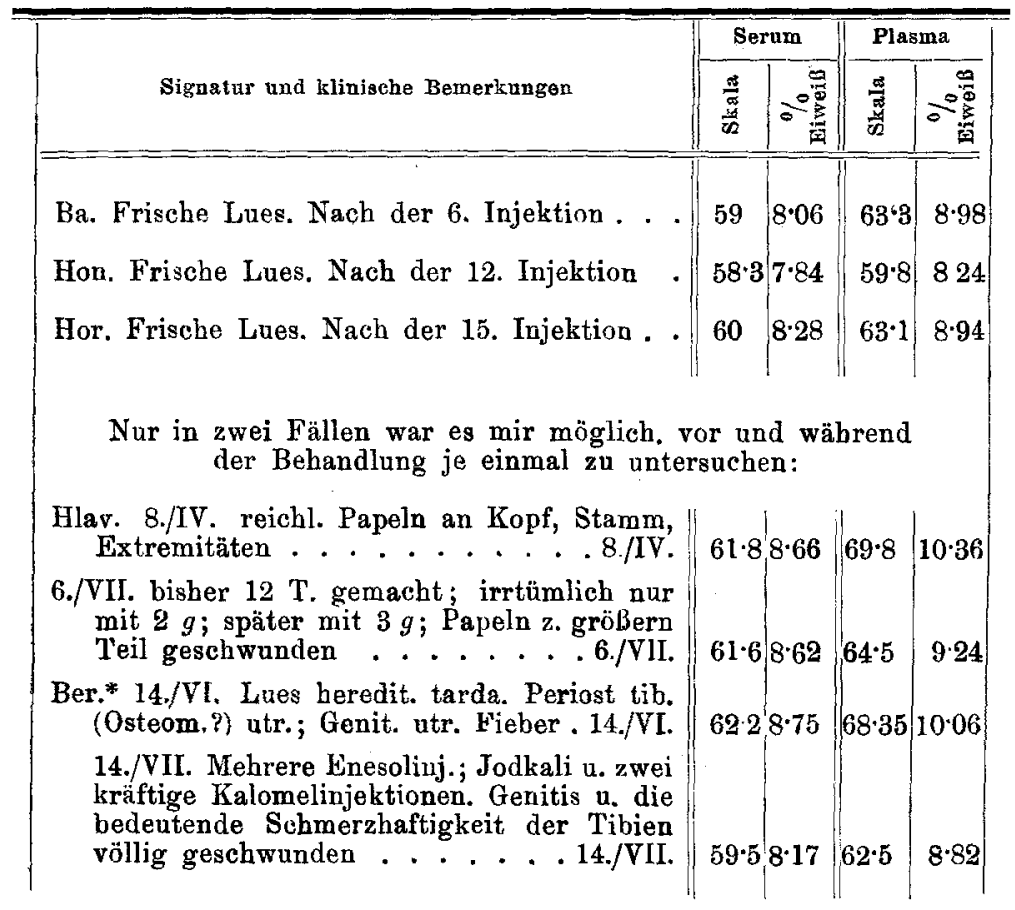

\section{Ergebnisse.}

Der Eiweißgehalt des Blutes (Serum und Plasma) zeigt bereits in der 2. Inkubationsperiode eine leichte Steigerung. Im Stadium der Exantheme lassen bis dahin unbehandelte Fälle und zwar namentlich solche mit reichlich ausgebildeten papulösen Effloreszenzen ein weiteres Ansteigen des Eiweißgehaltes im Serum und Plasma nachweisen. Auch die Differenz dieser 
beiden Werte, das Fibrinogen, bietet schon in der 2. Inkubationsperiode eine zwar sehr geringe, im ausgesprochenen papulösen Stadium eine deutliche Vermehrung gegenüber jener bei Gesunden. Auf der Höhe der Erkrankung kann die Steigerung des Gesamteiweib in $100 \mathrm{~g}$ Serum $0.64-0.85 \%$, in $100 \mathrm{~g}$ Plasma 0.8 bis $1.09 \%$, jene des Fibrinogens $0.24 \%$ betragen, d. i. 10, 15, resp. $25 \%$ der Normalmengen der betreffenden Stoffe.

Bei gummöser Lues sind nicht konstante Verhältnisse vorhanden; es ist möglich, daß unbehandelte frühgummöse Formen größere Eiweißwerte im Serum und Plasma geben, jene einer späteren Zeit namentlich bei geringer Entwicklung gummöser Veränderungen normale Eiweißziffern zeigen, Dasselbe gilt von Latenzstadien. Blut von Patienten im 7.-30. Infektionsjahr gab normale oder eher kleinere Zahlen; in einigen Fällen waren neben verdächtigen oder deutlicheren Luessymptomen leichtere oder größere Steigerungen der Eiweißwerte vorhanden.

Behufs Beurteilung voranstehender Ergebnisse ist ein Überblick über unsere Kontrollen und Methodik sowie eine Vergleichnng mit andeken bei der Lues erhaltenen Resultaten nützlich.

$\mathrm{DaB}$ ich als Kontrolle bloß normale, nicht auch Fälle verschiedener Erkrankungen verwendet habe, scheint fast einem Verzicht auf spezifische Charakterisierung gleichzukommen. Dies liegt aber an der benutzten Mehode.

Bei ihrer Schärfe, die sie (nach Strubell und Reiss) der Wägungsmethode gleich setzen läßt, ihrer Empfindlichkeit, welche - wie man beim Arbeiten leicht erfährt - kleinste Änderungen der Dichte (Verdunstung), Temperatur, Arbeitsdauer zum Ausdruck bringt, ist es klar, daB ihre Ergebnisse auch von zahlreichen physiologischen Varianten, wie Hunger, Nahrungsaufnahmen (besonders von Eiweißstoffen und Getränken), Menstruation, Alter u. a. abhängen werden, Momenten, die übrigens gegenwärtig refraktometrisch noch nicht genügend untersucht sind.

Bei vergleichender Heranziehung anderer Erkrankungen hätten aber die eben genannten Verhältnisse berïcksichtigt werden müssen, was bisher nicht geschehen ist und demnach das Untersuchungsgebiet für mich zu sehr ausgedehnt hätte. 
Als spezifische, für Luesdiagnose entscheidende Methode ist diese quantitative Methode nicht geeignet, doch kann sie durch Feststellung gewisser Momente, wie der relativen Mengenverhältnisse der einzelnen Eiweißfraktionen oder der zeitlichen Verhältnisse im Ablaut der Mengenänderungen zu einer Charakterisierung meiner Befunde gegenüber anderen pathologischen führen. In dieser Richtung habe ich neben der bereits von Halliburton bis Moll geübten Serumuntersuchung auch die von L. Langstem, P. Müller und a. als wichtig erkannte Plasmauntersuchung geübt und konnte so einerseits auch refraktometrisch die Vermehrung einer im Serum vorhandenen oder vielleicht neu auftretenden, bei Lues als Fibrinoglobulin von $\mathrm{Kreibich}$ ) angesprochenen Eiweilfraktion, als der im Plasma rorhandenen Gesamteiweißmenge nachweisen, in welcher letzteren auch die früher von mir beobachtete Steigerung des Fibrinogens enthalten ist. Die aus meinen Beobachtungen erhellende Wahrscheinlichkeit, daß die Eiweißvermehrung im Blute durch längere Zeit, bei unbehandelten Fällen vielleicht sehr lange zu finden sein wird, ist, weil dem chronischen Verlauf der Lues entsprechend, ebenfalls von einem gewissen charakterisierenden Wert. Letzterer ergibt sich auch, wenn man die hier gewonnenen graduellen Befunde hinsichtlich ihres Zusammenfallens mit den Stadien der Lues und einzelnen, als spezifisch geltenden Befunden und Reaktionen beurteilt, so mit der Reaktion von Wassermann-Neisser-Bruck und jener von Klausner.

Graduelle Zunahme des Eiweißes im Blute von der 2. Inkubation an und durch das Sekundärstadium (namentlich bei unbehandelten, hochgradigen Fällen) korrespondiert mit der Häufigkeit des positiven Ausfalles der genannten Reaktionen in diesen Krankheitsperioden, ebenso wie Zurückgehen dieser Eiweißvermebrung in späteren Stadien (Behandlungs-, gummöseund Latenzperiode) mit der Abnahme positiver Reaktionen von Wassermann und Klausner gleichlauft. Auch das Ausbleiben dieser Vermehrung in manchen Fällen frischer Lues sowie Auftreten derselben bei anderen Erkrankungen kann der

1) Verh. d. D. Dermat. Ges. X. Kongr. p. 168. 
Vergleichung nicht Eintrag tun, da dieselben Unstimmigkeiten bei den genannten Reaktionen beobachtet werden und überdies Eiweißvermehrung oder -verminderung Symptome viel allgemeinerer Natur sind.

Was speziell die Wassermannsche Reaktion betrifft, so drängte sich auch in meinem kleinen, hiefür verwendbaren Material eine gewisse Übereinstimmung ihrer Resultate mit jenen der Eiweißuntersuchung bei verschiedenen Fällen auf.

So fielen in 2 frischen Luesfällen kleine Eiweiszahlen mit einer unbestimmten, resp. schwach positiven Wassermannreaktion zusammen, in einem Falle korrespondierten hohe Eiweißzahlen, stark positiver Wassermann und lebhafte Erkrankungssymptome vor der Behandlung und Absinken der Eiweibzahlen, schwach positiver Was sermann und auffallende Besserung der klinischen Symptome nach einem Monat kräftiger Behandlung; besonders auffallend stimmten aber bei den Latenzfällen kleine Eiweibzahlen zu dem negativen Ausfall der W a s s e r m a n nproben und eine mäßige oder deutliche Erhöhung der Eiweißzahlen zu einem schwach oder deutlich positiven Ergebnis der Komplementbindungsreaktion. Mit einer recht großen Wahrscheinlichkeit und meist richtig habe ich nach Ausführung der refraktometrischen Eiweißbestimmung das Resultat der $W$ assermannprobe in den einzelnen Fällen vorausgesagt.

Daß dennoch eine absolute Kongruenz von Eiweißmengen im Blute und Ausfall ron Wassermann (oder Klausner) nicht besteht, zeigten einige Fälle frischer Lues, wo kleine Eiweißzahlen im Blute und trotzdem positive Reaktion von Wassermann (oder Klausner) vorhanden war, ein Beweis für die bei weitem größere Spezfizität der genannten Reaktion gegenüber der Eiweißveränderung.

Ich kann daher $\mathrm{N}$ o g u c c h i, ${ }^{1}$ ) der vor kurzem über regelmäßige Globulinvermehrung im luetischen Blute berichtet hat, darin nicht beistimmen, daß dieser Befund, beweisender für Lues sei als die W assermannreaktion, schon deshalb nicht, weil die Eiweißrermehrung ein bei weitem allgemei-

1) Nogucchi. Journ. of. Amer. Assoc. 12. Juni 1909 ref. Dentsche med. W. 1903, Nr. 35, p. 1247. 
neres Symptom ist und bei ihrem Vorhandensein viel mehr Momente ausgeschlossen werden müssen, als bei einer positiven $\mathrm{W}$ as serman n reaktion.

Trotz dieser Einschränkung verdient aber die Untersuchung der Eiweißrerhältnisse im Blute Luetischer Interesse und Bearbeitung. Sie gibt einen positiven chemischen Ausdruck für die Beeinflussung der kolloiden Blutbestandteile durch die Lues, die wohl durch die Affektion der blutbildenden Organe (Lymphdrüsen, Milz, Knochenmark), aber auch zahlreicher Körpergewebe bedingt ist. In dem zeitlichen Zusammenfallen der Eiweißvermehrung mit der beginnenden Durchseuchung, ihrem Ansteigen in der aktirsten Periode der Lues, ihrem Schwinden in der späten symptomlosen Latenzzeit ist ein $\mathrm{Zu}$ sammenhang mit Reaktions- oder Immunkörperbildung auch für die Lues ersichtlich, wie ähnliches bei anderen Intektionskrankheiten bekannt ist. Sie kann somit als quantitativer Ausdruck einer durch die Luesinfektion bedingten Antikörperbildung') angesehen werden, als deren qualitativer sich die Wassermann- (und im geringeren Grade, weil alıgemeiner. als erstere auch die Klausner-) Reaktion darstellt. Ist doch die Eiweißnatur der komplementbindenden Stoffe der W a s s ermannnprobe durch bereits vorliegende Untersuchungen ${ }^{2}$ ) nahe gelegt, ebenso wie für Antikörper bei Infektions- und Immunisierungsvorgängen überhaupt.

Neben solchen Antikörpern sind aber in den vermehrten Eiweißstoffen des Blutes Stoffwechselprodukte der Krankheitserreger, resp. Zerfallsstoffe der affizierten Gewebe zu vermuten; und erwägt man, daß die beobachteten Veränderungen des Blutes von äbnlichen in den Körpergeweben abhängen und begleitet werden, die zeitweise wohl nur geringfügig, aber über Jahre sich erstrecken können, so bedeutet dies eine sehr beachtenswerte Veränderung im Eiweißhaushalt des Körpers. Der Grad dieser Veränderung dürfte natürlich ebenso außerordentlich variieren, als der in den einzelnen Fällen so verschiedene Verlauf der Lues sinnfällig nahelegt.

1) Weil und Braun. Wiener kl. Woch., 1909, Nr. 11, sehen die komplementbindenden Stoffe im luetischen Serum für Reaktionsprodukte gegen körpereigene Zellbestandteile an.

a) Bau er. Biochem. Zeitschr. 1908. 